\title{
Electrically Activated Paper Actuators
}

\section{Citation}

Hamedi, Mahiar M., Victoria E. Campbell, Philipp Rothemund, Firat Güder, Dionysios C. Christodouleas, Jean-Francis Bloch, and George M. Whitesides. 2016. Electrically Activated Paper Actuators. Advanced Functional Materials 26, no. 15: 2446-2453. Portico. doi:10.1002/ adfm.201505123.

\section{Published Version}

10.1002/adfm.201505123

\section{Permanent link}

http://nrs.harvard.edu/urn-3:HUL.InstRepos:30353766

\section{Terms of Use}

This article was downloaded from Harvard University's DASH repository, and is made available under the terms and conditions applicable to Open Access Policy Articles, as set forth at http:// nrs.harvard.edu/urn-3:HUL.InstRepos:dash.current.terms-of-use\#OAP

\section{Share Your Story}

The Harvard community has made this article openly available.

Please share how this access benefits you. Submit a story.

\section{Accessibility}




\section{WILEY-VCH}

DOI: 10.1002/ ((please add manuscript number))

Article type: Full Paper

\section{Electrically Activated Paper Actuators}

Mahiar M. Hamedi, ${ }^{\dagger}$ Victoria E. Campbell,,$^{\dagger}$ Philipp Rothemund, Firat Güder, Dionysios C. Christodouleas, Jean-Francis Bloch, George M. Whitesides*

Dr. M. M. Hamedi, Dr. V. E. Campbell, P. Rothemund, Dr. F. Guder, Dr. D. C.

Christodouleas, Prof. G. M. Whitesides

Department of Chemistry and Chemical Biology, Harvard University, Cambridge MA, USA

${ }^{\dagger}$ Both authors contributed equally to this work.

E-mail: gwhitesides@gmwgroup.harvard.edu

Dr. V. E. Campbell

Institut de Chimie Moléculaire et des Matériaux d'Orsay, CNRS, Université Paris Sud 11, 91405 Orsay Cedex, France.

P. Rothemund

School of Engineering and Applied Sciences, Harvard University, Cambridge, MA 02138, USA.

P. Rothemund, Prof. G. M. Whitesides

Kavli Institute for Bionano Science and Technology, Harvard University, Cambridge MA 02138, USA.

Prof. J.-F. Bloch

Grenoble Institute of Technology, The International School of Paper, Print Media and Biomaterials (PAGORA), France

Prof. G. M. Whitesides

Wyss Institute for Biologically Inspired Engineering, Harvard University, Cambridge, MA, USA

Keywords: actuators, paper, PEDOT 


\section{WILEY-VCH}

This paper describes the design and fabrication of electrically controlled paper actuators that operate based on the dimensional changes of that occur in paper when the moisture absorbed on the surface of the cellulose fibers changes. These actuators are called "Hygroexpansive Electrothermal Paper Actuators" (HEPAs). The actuators are made from paper, conducting polymer, and adhesive tape. They are lightweight, inexpensive, and can be fabricated using simple printing techniques. The central element of the HEPAs is a porous conducting path (used to provide electrothermal heating) that changes the moisture content of the paper and causes actuation. This conducting path is made by embedding a conducting polymer (PEDOT:PSS) within the paper, and thus making a paper / polymer composite that retains the porosity and hydrophilicity of paper. Different types of HEPAs (straight, pre-curved, and creased) achieved different types of motions (e.g., bending motion, accordion type motion). A theoretical model for their behavior is proposed. These actuators have been used for the manipulation of liquids, and for the fabrication of an optical shutter.

\section{Introduction}

Paper is an abundant, lightweight, and biodegradable material that has been used for centuries for printing, packaging, and absorbing liquids. Paper is a porous hydrophilic network of intertwined cellulose fibers. ${ }^{[1]}$ This network defines the mechanical and fluidic properties of the material. ${ }^{[2]}$ In recent years, paper has become increasingly interesting as a material in new applications. ${ }^{[3-5]}$ For example, we and others have used it for microfluidic ${ }^{[6-}$ ${ }^{10]}$ and electroanalytical devices as the basis for low-cost diagnostics, ${ }^{[11,12]}$ as 3-D scaffolds for cell growth, ${ }^{[13-15]}$ as a substrate for printed electronics, ${ }^{[16-22]}$ and in micro-electromechanical systems (MEMS). ${ }^{[16,23,24]}$ A missing component for paper-based devices is an electrically controlled actuator that is embedded within the paper, can be fabricated by printing, and continues to operate when the paper that supports it is creased and/or folded. Paper actuators that fulfill these requirements have the potential to allow control of liquid transport in paperbased microfluidic devices, to enable assembly of micro machines through self-folding, ${ }^{[24-26]}$ 


\section{WILEY-VCH}

and to serve as microactuators for paper devices. ${ }^{[25,27]}$ If mechanical work could be performed with paper actuators, we could build new kinds of "paper-based machines".

Given the attractive properties of paper, there has been surprisingly little research done on the fabrication of paper actuators. ${ }^{[28]}$ Three examples are: (i) Paper-based actuators made by integrating magnetic particles in paper. The actuation in these systems is achieved by (and requires) an external magnetic field. ${ }^{[29,30]}$ This approach produces tunable composite materials, but requires large quantities of magnetic additives that are controlled by the application of a localized external magnetic field: this control is difficult and/or inconvenient to accomplish. (ii) Electrostatic zippers. These actuators consist of two sheets of paper that are coated with carbon nanotubes and are separated by a dielectric layer. They actuate using electrostatic fields. ${ }^{[31]}$ The paper zippers are simple in design, and low in cost, but have the disadvantage that they require several kilovolts to actuate, and deliver only small movement. (iii) Electroactive papers. ${ }^{[32-34]}$ These structures are fabricated by printing electrodes (usually made from gold) on both sides of paper or of cellulose films. They are lightweight, and flexible, but have the drawback that they require metallic electrodes. This requirement adds to both their cost and complexity. Their performance also degrades over time, and they do not function when creased. Because paper is hydrophilic, most systems based on it are affected by the relative humidity $(\mathrm{RH})$ of the environment.

This paper describes the design and fabrication of electrically controlled paper actuators that exploit the hygroexpansive properties of paper; they expand or contract based on changes of moisture within the paper. We call these actuators "Hygroexpansive Electrothermal Paper Actuators" (HEPAs). Figure 1 shows a schematic representation of the four different types of HEPAs (straight, pre-curved, creased-curved, and creased-sawtooth) that we fabricated and characterized. These simple devices are made from paper, conducting polymer, and adhesive tape. They are lightweight and inexpensive, and they continue to operate when bent and scratched. We describe a theoretical model for their behavior, show that the actuation of the 


\section{WILEY-VCH}

HEPAs is reversible over a large range of relative humidity, and demonstrate that they can be designed to move along either a straight or curved path. We show that these actuators can be used for the manipulation of liquids, and for the fabrication of an optical shutter.

\section{Results and Discussion}

Design and fabrication. Figure 1 sketches the fabrication of the HEPAs. The general fabrication process is as follows. We wax printed a fluidic U-shaped channel on paper. ${ }^{[35]}$ Using a pipette, we added to the paper a suspension of the conducting polymer (PEDOT:PSS) in water. The PEDOT:PSS suspension wicks into the predefined channel, and upon drying coats the cellulose fibers throughout the thickness of the paper sheet (rather than localizing on the surface, as seen from optical, and scanning electron microscope images; Figures $1 \mathrm{~b}, \mathrm{c}, \mathrm{d}$, and S1). When dry it forms a conducting paper/PEDOT:PSS composite, which we used to provide electrothermal heating. We note that without the patterned wax barrier (which also spans the width of the paper) the PEDOT:PSS suspension would spread unevenly across the paper by capillary wicking, and would not form a well-defined conducting path. To direct actuation, we attached pieces of $\operatorname{Scotch}{ }^{\circledR}$ tape $(40 \mu \mathrm{m}$ thick), either on one side of the paper yielding the straight, pre-curved or creased-curved HEPAs - or on alternating sides - yielding the creased-sawtooth HEPA - (Figure 1e). The final step consists in designing the form of the HEPA. We fabricated two shapes: i) the pre-curved HEPA fabricated by manually curling one side of the straight HEPA, using a dull blade (similar to curling a ribbon ${ }^{[36]}$ ); ii) the creasedcurved HEPA fabricated by manually folding the straight HEPA.

The HEPAs operate because of the moisture-induced dimensional changes of the paper/PEDOT:PSS composite, and the absence of moisture-induced dimensional changes of the tape. When the resistive heating element is turned on, the composite heats, the moisture content of the paper is reduced, and the paper component of the composite contracts. When the resistive heating element is turned off, the composite absorbs moisture from the environment, the moisture content of the paper increases, and the composite returns to 


\section{WILEY-VCH}

approximately its original shape. Since the tape is unaffected by moisture and heat (even up to $100{ }^{\circ} \mathrm{C}$ ), it acts as the strain-limiting layer, thus the dimensional changes of the paper/PEDOT:PSS composite are translated into a bending motion.

We designed four types of HEPAs (straight, pre-curved, creased-curved and creasedsawtooth) that can perform a range of motions. Figure 1e shows schematic representations of the four types of HEPAs, and their initial (the electrothermal element is off, OFF state) and final (the electrothermal element is on, ON state) positions. For example, the initial position (OFF state) of a straight HEPA is straight and then it bends to a certain angle to reach its final position (ON state). A pre-curved HEPA, conversely, can perform the exact opposite motion compared to a straight HEPA; its initial position is curved, and its final position is straight (Figure 1e). The creased configurations of the HEPAs can perform more complex motions (e.g., angular and accordion-type motions) as each crease changes its angle independently. The total motion, therefore, is the sum of the change in angular motion of each individual crease. The exact motion of each configuration of HEPA is influenced by three parameters: (i) the consumed power; (ii) the dimensions of the actuators; (iii) the relative humidity of the environment. In the following sections we examined in detail the effect of each of these parameters (Figures 3, 5, 6 and $\mathbf{S 2}$ show photographic images of the HEPAs during actuation).

Consumed power, resistance and driving voltage. The conducting paper/PEDOT:PSS composite is used as a resistive element to generate the heat necessary for a change in the moisture content - and in turn for actuation - of the HEPA. The speed of actuation is proportional to the heat generated (greater heat $=$ faster actuation), and this heat is related to the power consumed, the resistance, and the driving voltage of the paper/PEDOT:PSS composite. Using infrared (IR) thermal images, we concluded that temperatures of $80{ }^{\circ} \mathrm{C}$ are high enough to generate maximum and fastest actuation at the lowest consumed power. To study the heat distribution, we recorded the thermal profile of the paper/PEDOT:PSS 


\section{WILEY-VCH}

composite, using an IR camera, at different applied voltages, and recorded the corresponding power $(P)$. The IR images indicated that at each voltage the temperature was uniform across the surface of the resistive element, and the heat dissipated into the wax barrier (Figure 2). We note that we did not observe any degradation in the paper/PEDOT:PSS composite (i.e. it did not dissolve or burn) when we increased the temperature to $100^{\circ} \mathrm{C}$ for 10 minutes (this time is much longer than the required time for our actuation experiments). We calculated the normalized power per area $\left(P_{n}\right)$, using $P_{n}=P / L W \mathrm{Pn}=\mathrm{P} / \mathrm{LW}$ (we used $P_{n}$ because it is independent of the size of the actuator, and is directly related to the temperature), and we concluded that we need $P_{n}=0.3 \mathrm{Wcm}^{-2}$ to reach a temperature of $80^{\circ} \mathrm{C}$.

Power is related to voltage and resistance through Ohm's law $\left(P=V^{2} / R\right)$. We measured the sheet resistance $\left(R_{S}\right)$ across the conductive paper/PEDOT:PSS channel at room temperature at different PEDOT:PSS loading. The sheet resistance is a parameter that is independent of the length, $L$, and the width, $W$, of the HEPA $\left(R_{S}=R W / 4 L\right)$. As expected, the resistance lowered with increased PEDOT:PSS loading (the lowest sheet resistance we obtained was $\left.R_{S}=70 \Omega / \mathrm{sq}\right)$. For our experiments we fabricated HEPAs with sheet resistance at room temperature of around $350 \Omega /$ sq.

The driving voltage of the actuator can be expressed as a function of the sheet resistance and normalized power $\left(V=2 L \sqrt{P_{n} R_{S}}\right)$. From this relation, we note that actuators with lower sheet resistance, and/or shorter length, operate at lower driving voltage for the same power per area (note that the driving voltage is independent of the width of the HEPA). In this study, we could, for example, actuate HEAPs with different dimensions (at $P_{n}=0.3 \mathrm{Wcm}^{-2}$ ) at driving voltages between $20 \mathrm{~V}$ (for actuators with $\mathrm{W}=1 \mathrm{~cm}$, and $\mathrm{L}=3 \mathrm{~cm}$ ) and $100 \mathrm{~V}$ (for $\mathrm{W}=1$ $\mathrm{cm}$, and $\mathrm{L}=10 \mathrm{~cm})$.

Since the resistance changes with temperature, we calculated the sheet resistance as a function of power (and thus temperature). We plotted $R(T) / R_{0}$, where $R_{0}$ is the resistance at 


\section{WILEY-VCH}

room temperature, and noted that the resistance decreased by less than $10 \%$ at the highest temperature (Figure 2c). We, thus, concluded that the change in resistance does not have any significant effect on the performance of the actuator, and, that we can therefore approximate the resistance as constant for a given dimension.

Theoretical model of the motion. To understand the behavior of HEPAs, we developed an analytical mechanical model (see SI). This model relates the curvature $(\kappa)$ of the bi-layer actuator to the temperature-induced strain $\varepsilon_{\mathrm{h}}$ of the paper by Equation 1.

$$
\kappa=\frac{6 \varepsilon_{h} E_{1} E_{2} t_{1} t_{2}\left(t_{1}+t_{2}\right)}{\left(E_{1} t_{1}^{2}-E_{2} t_{2}^{2}\right)^{2}+4 E_{1} E_{2} t_{1} t_{2}\left(t_{1}+t_{2}\right)^{2}}
$$

Here, $t$ is the thickness, and $E$ is the Young's modulus, for the paper layer $\left(t_{l}, E_{l}\right)$, and the tape layer $\left(t_{2}, E_{2}\right)$. This result is analogous to a bi-layered beam under thermal expansion, but instead of a thermal strain, this model uses the hygroexpansive strain $\left(\varepsilon_{\mathrm{h}}\right)$ defined as the ratio between the changes in length to initial length as a function of moisture content $\left(m_{c}\right)$. In certain regions $\varepsilon_{\mathrm{h}}$ is a linear, and reversible, function of the moisture content ${ }^{[37]}$ described by Equation 2 where $\beta$ is defined as the hygroexpansion coefficient, and $\Delta m_{c}$ is the change in the moisture content.

$$
\varepsilon_{h}=\beta \Delta m_{c}
$$

A typical value of $\beta$ for many types of paper is approximately $0.1 .^{[37,38]}$ By using Equation 1, and the largest curvature that we measured $\left(0.12 \mathrm{~cm}^{-1}\right)$, we calculated $\varepsilon_{\mathrm{h}}=0.3 \%$ for a HEPA with $\mathrm{L}: \mathrm{W}=10: 1$ (see SI). This value is in agreement with the reported values for the hygroexpansion of paper. ${ }^{[39]}$ In reality, $E_{l}$ can also change with the moisture content (the paper becomes stiffer as it dries), but the change in $E_{l}$ has a small effect on $\kappa$, and we assume $E_{1}$ to be constant. Equation 1 can also be used to optimize the relation between $t_{1}, t_{2}$ and $E_{2}$, and to design a HEPA that has maximum bending curvature for a given type of paper (with fixed thickness and elastic modulus). 


\section{WILEY-VCH}

Influence of the dimensions of the HEPAs on actuation, and generated force. Equation 1 predicts that the curvature of actuation, at constant temperature, is independent of the length of the actuators. Our experiments, however, showed that this predictions only holds true for longer actuators ( $\mathrm{L}: \mathrm{W}$ ratios $\geq 3$ ). Short actuators show a smaller, length-dependent actuation (see Figure S2). We reasoned that the boundary effects become important for shorter actuators, to the point that Equation 1 is no longer valid, and the actuators displace by a smaller percentage (at the same power) than do longer ones. In this work, we only focused on actuators with large $\mathrm{L}: \mathrm{W}$ ratios $(>3)$ at an on-state temperature of around $80{ }^{\circ} \mathrm{C}$.

In addition to the movement of the HEPAs, we also measured their static force, (at the tip of the actuators) using a straight HEPA. The largest specific force (force/total weight of the HEPA) was measured to $\sim 0.07 \mathrm{~N} / \mathrm{g}$ (see Table 1). In contrast with the results from the free actuation (without any loading), the specific force of the actuators increased as the L:W ratio decreased. This behavior is expected because the stiffness (spring constant) of a bending beam increases with a decrease in length, which allows the actuator to generate a larger force. A noteworthy point about these results is that HEPAs can lift weights that are larger than their own weights. For example, the shortest actuator can lift around 20 times $(0.57 \mathrm{~g} / 0.027 \mathrm{~g})$ its own weight. We demonstrate this structure with the fabrication and operation of an optical shutter described in below.

Humidity Dependence. Because HEPAs actuate due to moisture-induced dimensional changes of the paper/PEDOT:PSS composite, we studied the influence of RH on the motion of bending, on the range of actuation, and on the speed of actuation (Figure 3 and 4). As shown in Figure 3, we operated the same HEPA in two environments of different humidity: i) dry $(\mathrm{RH}=15 \%)$, and ii) humid $(\mathrm{RH}=85 \%)$. We started the experiment at low $\mathrm{RH}(15 \%)$. When we turned on the electrothermal element, moisture evaporated from the paper/PEDOT:PSS composite, the HEPA moved down, and the extra paper section (attached to the end of the HEPA) contacted and absorbed a droplet of a solution of a blue dye (Figure $3 \mathrm{~b}$ ). When we 


\section{WILEY-VCH}

turned off the electrothermal element, the HEPA returned to its original position (Figure $3 \mathrm{c}$ ). We then increased the RH to 85\%, and repeated the experiment (Figure 3d, e, and f). At this $\mathrm{RH}$, the paper/PEDOT:PSS composite absorbed more ambient moisture, which resulted in an initial state (off-state) with greater curvature (Figure 3d). Its final state (on-state), however, was not visibly affected by the increase in $\mathrm{RH}$, and the actuator picked up a solution of a red dye (Figure 3e). We tested the speed of actuation and recovery of the same HEPA at seven different RH (15-85\%) and P = 1W (Figure 4). We note that for the same HEPA (L:W = $10: 1 \mathrm{~cm}$ ) the speed of actuation, and of recovery is not noticeably affected by the RH. (Figure 4, and Movies M1-8). We also tested the HEPA at $\mathrm{RH}=35 \%$ and $\mathrm{P}=2 \mathrm{~W}$, and we note that the speed of actuation (18s) and of recover (16s) are not influenced by this difference in power. These experiments demonstrates that (i) the HEPAs can move weights (in the form of a paper appendix, and water droplets), (ii) the HEPAs actuate over a wide range of values of $\mathrm{RH}$, because electrothermal heating releases the majority of the moisture absorbed in the paper irrespective of RH, and (iii) the speed of actuation of the HEPAs is not noticeably affected by the RH or the consumed power.

Creased HEPAs. An attractive property of HEPAs is, that they function even when folded / creased. Unlike other paper actuators (fabricated with metallic conductors on the surface of the paper), HEPAs do not break, upon repeated creasing when subject to high strain on bending. To test the influence of creasing on the paper/PEDOT:PSS composite, we fabricated a conducting path $(1 \mathrm{~mm}$ by $18 \mathrm{~cm})$, folded it 11 times, and measured its resistance as a function of the fold angle (Figure S3). The resistance changed less than $10 \%$ between the unfolded and folded structures, even after 1000 open / close cycles (Figure S3). Figure 5a shows time-lapse photographs of the creased-curved HEPA that operated by closing and opening the half circular shape. This HEPA closed at a greater angle than the pre-curved variations, and could lift a weight (a piece of paper, $\mathrm{m}=46 \mathrm{mg}$ ). 


\section{WILEY-VCH}

Figure $5 \mathrm{~b}$ shows time-lapse photographs of a creased-sawtooth HEPA that was creased in an accordion-shape. The difference between these two designs was the position of the tape. When the tape is positioned on one side of the paper/PEDOT:PSS composite, the angular motion of each crease is in the same direction; this concerted motion resulted in curving (Figure 5a, and Movies M9-M10). When we positioned the tape on alternate sides of the composite, the cumulative angular motion resulted in linear actuation (Figure 5b), which is an essential motion in many mechanical machines.

Proof-of concept of application: a paper optical shutter. Figure 6 shows a pre-curved HEPA that acts as an optical shutter. We designed this HEPA to have an almost semi-circular shape, with an extra paper section (shutter), and mounted it onto a backlit table (Figure 6). When the electrothermal element was off, the shutter covered the hole and blocked the light. When we turned the electrothermal element on, the shutter moved, uncovered the hole, and allowed the light to pass through (Figure 6c). The shutter opened in 8 seconds, and closed in 16 seconds (at room temperature and $\mathrm{RH}=40 \%$, see time-lapse photographs in Figure $6 \mathrm{c}$, and movie M11). We tested 260 open/close cycles and did not observe degradation of actuation (see Figure 6b).

\section{Conclusion}

Hygroexpansive Electrothermal Paper Actuators (HEPAs) made using paper, conducting polymer, and tape, can be actuated using the hygroexpansive properties of paper, and are controlled electrically by heating. The central element is the porous conducting path (used to provide electrothermal heating). This conducting path is made by coating the fibers in the paper (across the thickness of the sheet) with a conducting polymer (PEDOT:PSS) and thus making a paper/polymer composite that retains the porous and hydrophilic properties of paper. Upon electrothermal heating, the moisture content of the paper decreases, and the paper/polymer composite contracts. When the electrothermal heating element is turned off, the paper/polymer composite absorbs moisture from the environment (moisture content 


\section{WILEY-VCH}

increases), and expands. Using theoretical calculations, we have shown that HEPAs can operate over a range of voltages, and that a normalized power per area of $0.3 \mathrm{Wcm}^{-2}$ is suitable for achieving maximum actuation. We derived a mechanical model that relates the curvature of the actuator to its dimensions, material parameters, and hygoexpansion. We showed experimentally that this model could be used for actuators with a length to width ratio greater than three (actuators with $\mathrm{L}: \mathrm{W}<3$ are less power-efficient). We showed that the driving voltage of the HEPA was independent of $\mathrm{L}$, and that larger actuation required larger $\mathrm{L}: \mathrm{W}$ ratios. We measured a maximum specific static force of $0.07 \mathrm{~N} / \mathrm{g}$, and we showed that HEPAs with smaller L:W ratios have larger specific static force.

The HEPAs have four advantages: (i) They are lightweight, inexpensive, and biodegradable. (ii) They are easy to fabricate using simple printing techniques. (iii) They operate even when bent and scratched, because the element that provides electromechanical work is embedded within the paper. These features offer the possibility of designing complex folded structures. (iv) They can actuate many times without showing signs of degradation of performance. HEPAs are similar to other paper-based actuators, in that they have the disadvantage that their initial state is influenced by the relative humidity of the environment. Unlike most other paper-based actuators, however, their final state is not affected by relative humidity, as it is contingent on the electrothermal element drying the paper/polymer composites. They also have obvious shortcomings: they exert only small forces, and are relatively slow.

Due to their attractive properties (i.e. cost, weight, printability, and porosity), HEPAs could be useful in applications benefitting from monolithic integration in paper-based printed microfluidic ${ }^{[6-10]}$ and electronic devices, ${ }^{[16-22]}$ paper MEMS, ${ }^{[16,23,24]}$ printable and foldable micro machines, ${ }^{[24-26]}$ and robots. ${ }^{[25,27,40]}$ Their speed of actuation, and the force they produce, however, is low (by standards of more conventional electromagnetic and pneumatic / hydrolic systems), but they are also lighter, much less expensive, and much more easily integrated with 


\section{WILEY-VCH}

paper devices (diagnostic, bioanalytical, and electromechanical systems, for example) than are the more universal systems. The systems in Figure 3, for example, might have the right characteristics to be used to sample a droplet medium in bioanalysis, and the one in Figure 5 to reposition a filter in a low-cost environmental monitor. These systems have the functional advantage that they can be reconfigured by folding and creasing without damaging them. The ability to fabricate small (sub mm-scale) porous wires of PEDOT:PSS that extend across the full thickness of a sheet of paper by using capillary wicking of an aqueous suspension of PEDOT:PSS into a channel defined by wax-printed walls, is a new fabrication technique with the potential for wide application in paper-based devices and machines, especially when folding and creasing are an issue. ${ }^{[24-26]}$

\section{Experimental Section}

Materials .Poly(3,4-ethylenedioxythiophene):poly(styrenesulfonic acid) (PEDOT:PSS solution $10 \%$ in water) Clevios ${ }^{\mathrm{TM}} \mathrm{PH} 1000$ was purchased from Heraeus, and mixed with 5 $\mathrm{wt} \%$ dimethylsulfoxide (DMSO). PEDOT:PSS is stable in ambient conditions, and upon drying, it forms thin films that are highly conducting $(>1000 \mathrm{~S} / \mathrm{cm}),{ }^{[41]}$ and resilient to bending and stretching. ${ }^{[42]}$ Whatman ${ }^{\circledR}$ Chromatography Paper Grade A was purchased from Sigma Aldrich. Scotch ${ }^{\circledR}$ tape $(40 \mu \mathrm{m}$ thick) was used as the strain-limiting layer to direct the movement of actuation. This tape was unaffected by moisture and heat (even up to $100^{\circ} \mathrm{C}$ ). Fabrication of HEPAs. The devices were fabricated by printing wax patterns with a Xerox ColorQube and melting, the wax into the paper by placing the sheet of paper in an oven at $140{ }^{\circ} \mathrm{C}$ for 2 minutes. We then added the PEDOT:PSS solution with a pipette to the channels that were defined by the wax. The patterned actuators were cut, and a layer of Scotch ${ }^{\circledR}$ tape was attached to obtain the HEPA.

Electrical operation. A Keithly 2410 source-meter was as a digital multimeter, and as a power source to deliver the power for resistive heating. The HEPAs were connected to the sourcemeter with copper alligator clips. 


\section{WILEY-VCH}

Thermal characterization. Thermal images were acquired using a FLIR T600-Series infrared imaging camera.

Control of relative humidity. RH was controlled with two mass flow controllers [MKS 1179 A $-1,000 \mathrm{sccm}$ and $10,000 \mathrm{sccm}]$, using LabView ${ }^{\circledR}$, to regulated the flow of nitrogen (to dry) and water vapor (to humidify) at different ratios into a glass chamber.

Calculation of optical shutter intensity. MATLAB ${ }^{\circledR}$ was used for calculating the light intensity from each frame of a video from the optical shutter. The intensity was calculated as the average gray-scale intensity of pixels corresponding to the circular optical window.

\section{Supporting Information}

Supporting Information is available from the Wiley Online Library or from the author.

\section{Acknowledgements}

M. M. H. acknowledges support from Marie Curie IOF FP7 for project nanoPAD (Grant Agreement Number 330017). P. R. acknowledges support from MRSEC (DMR 14-20570).

F.G. thanks German Research Foundation (GU 1468/1-1) for research support. D.C.C acknowledges support from Defense Threat Reduction Agency (award number HDTRA1-14C-0037).

Received: ((will be filled in by the editorial staff))

Revised: ((will be filled in by the editorial staff)) Published online: ((will be filled in by the editorial staff))

[1] W. Scott, A. C. James, S. Trosset, Properties of Papers: An Introduction, Second Edition, Tappi Pr, 1997.

[2] A. Dwan, J. Am. Inst. Conserv. 1987, 26, 1.

[3] D. Klemm, B. Heublein, H. Fink, A. Bohn, Angew. Chemie Int. Ed. 2005, 44, 3358.

[4] L. Hu, J. W. Choi, Y. Yang, S. Jeong, F. La Mantia, L.-F. Cui, Y. Cui, Proc. Natl. Acad. Sci. U. S. A. 2009, 106, 1.

[5] V. L. Pushparaj, M. M. Shaijumon, A. Kumar, S. Murugesan, L. Ci, R. Vajtai, R. J. Linhardt, O. Nalamasu, P. M. Ajayan, Proc. Natl. Acad. Sci. U. S. A. 2007, 104, 13574. 


\section{WILEY-VCH}

[6] A. W. Martinez, S. T. Phillips, G. M. Whitesides, Proc. Natl. Acad. Sci. U. S. A. 2008, $105,19606$.

[7] E. J. Maxwell, A. D. Mazzeo, G. M. Whitesides, MRS Bull. 2013, 38, 309.

[8] D. M. Cate, J. A. Adkins, J. Mettakoonpitak, C. S. Henry, Anal. Chem. 2015, 87, 19.

[9] A. K. Yetisen, M. S. Akram, C. R. Lowe, Lab Chip 2013, 13, 2210.

[10] A. W. Martinez, S. T. Phillips, G. M. Whitesides, E. Carrilho, Anal. Chem. 2010, 82, 3.

[11] J. T. Connelly, J. P. Rolland, G. M. Whitesides, Anal. Chem. 2015, 87, 7595.

[12] A. Nemiroski, D. C. Christodouleas, J. W. Hennek, A. A. Kumar, E. J. Maxwell, M. T. Fernández-Abedul, G. M. Whitesides, Proc. Natl. Acad. Sci. U. S. A. 2014, 111, 11984.

[13] B. Mosadegh, B. E. Dabiri, M. R. Lockett, R. Derda, P. Campbell, K. K. Parker, G. M. Whitesides, Adv. Healthc. Mater. 2014, 3, 1036.

[14] B. Mosadegh, M. R. Lockett, K. Thu, K. A. Simon, K. Gilbert, S. Hillier, D. Newsome, H. Li, A. B. Hall, D. M. Boucher, B. K. Eustace, G. M. Whitesides, Biomaterials 2015, $52,262$.

[15] S. Burnham, J. Hu, H. Anany, L. Brovko, F. Deiss, R. Derda, M. W. Griffiths, Anal. Bioanal. Chem. 2014, 406, 5685.

[16] J. Lessing, A. C. Glavan, S. B. Walker, C. Keplinger, J. A. Lewis, G. M. Whitesides, Adv. Mater. 2014, 26, 4677.

[17] D. Tobjörk, R. Österbacka, Adv. Mater. 2011, 23, 1935.

[18] A. D. Mazzeo, W. B. Kalb, L. Chan, M. G. Killian, J. Bloch, B. A. Mazzeo, G. M. Whitesides, Adv. Mater. 2012, 24, 2850.

[19] L. Hu, H. Wu, Y. Cui, Appl. Phys. Lett. 2010, 96, 183502.

[20] A. Asadpoordarvish, A. Sandström, C. Larsen, R. Bollström, M. Toivakka, R. Österbacka, L. Edman, Adv. Funct. Mater. 2015, 25, 3238.

[21] Y. Zheng, Z. He, Y. Gao, J. Liu, Sci. Rep. 2013, 3, 1786.

[22] G. C. Schmidt, M. Bellmann, B. Meier, M. Hambsch, K. Reuter, H. Kempa, a. C. Hübler, Org. Electron. physics, Mater. Appl. 2010, 11, 1683.

[23] X. Liu, M. Mwangi, X. Li, M. O’Brien, G. M. Whitesides, Lab Chip 2011, 11, 2189.

[24] P. S. Sreetharan, J. P. Whitney, M. D. Strauss, R. J. Wood, J. Micromech. Microeng. 2012, 22, 055027.

[25] S. Felton, M. Tolley, E. Demaine, D. Rus, R. Wood, Science 2014, 345, 644. 


\section{WILEY-VCH}

[26] P.-K. Yang, Z.-H. Lin, K. C. Pradel, L. Lin, X. Li, X. Wen, J.-H. He, Z. L. Wang, ACS Nano 2015, 9, 901.

[27] C. D. Onal, R. J. Wood, D. Rus, IEEE Int. Conf. Robot. Autom. 2011, 4608.

[28] Q. Zhao, J. W. C. Dunlop, X. Qiu, F. Huang, Z. Zhang, J. Heyda, J. Dzubiella, M. Antonietti, J. Yuan, Nat. Commun. 2014, 5, 4293.

[29] Z. Ding, P. Wei, B. Ziaie, IEEE 23rd Int. Conf. Micro Electro Mech. Syst. 2010, 1127.

[30] R. T. Olsson, M. a S. Azizi Samir, G. Salazar-Alvarez, L. Belova, V. Ström, L. a Berglund, O. Ikkala, J. Nogués, U. W. Gedde, Nat. Nanotechnol. 2010, 5, 584.

[31] A. S. Chen, H. Zhu, Y. Li, L. Hu, S. Bergbreiter, IEEE Int. Conf. Robot. Autom. 2014, 5038.

[32] J. Kim, S. Yun, Z. Ounaies, Macromolecules 2006, 39, 4202.

[33] J. Kim, S. Yun, S. K. Mahadeva, K. Yun, S. Y. Yang, M. Maniruzzaman, Sensors 2010, 10, 1473.

[34] J. Kim, Y. B. Seo, Smart Mater. Struct. 2002, 11, 355.

[35] E. Carrilho, A. W. Martinez, G. M. Whitesides, Anal. Chem. 2009, 81, 7091.

[36] A. C. Callan-Jones, P.-T. Brun, B. Audoly, Phys. Rev. Lett. 2012, 108, 174302.

[37] T. Uesaka, J. Mater. Sci. 1994, 29, 2373.

[38] E. R. Mark, C. C. Habeger Jr., J. Borch, M. B. Lyne, Handbook of Physical and Mechanical Testing of Paper and Paperboard, Volume 1, Dekker, 1983.

[39] C. Borch, Jens, Lyne, M. Bruce, Mark, Richard E., Habeger, Handbook of Physical Testing of Paper, Volume 2, CRC Press, 2001.

[40] C. Sung, D. Rus, J. Mech. Robot. 2015, 7, 21012.

[41] O. Bubnova, Z. U. Khan, H. Wang, S. Braun, D. R. Evans, M. Fabretto, P. HojatiTalemi, D. Dagnelund, J.-B. Arlin, Y. H. Geerts, S. Desbief, D. W. Breiby, J. W. Andreasen, R. Lazzaroni, W. M. Chen, I. Zozoulenko, M. Fahlman, P. J. Murphy, M. Berggren, X. Crispin, Nat. Mater. 2014, 13, 190.

[42] M. Vosgueritchian, D. J. Lipomi, Z. Bao, Adv. Funct. Mater. 2012, 22, 421.

[43] S. Timoshenko, J. Opt. Soc. Am. 1925, 11, 233.

[44] W. W. Sampson, J. Yamamoto, J. Mater. Sci. 2010, 46, 541.

[45] T. Uesaka, J. Mater. Sci. 1994, 29, 2373. 


\section{WILEY-VCH}

Paper/PEDOT:PSS composite

Paper/wax

Tape

Paper

ii) PEDOT:PSS ink

a)

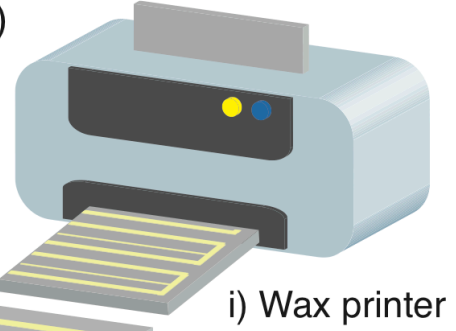

b)

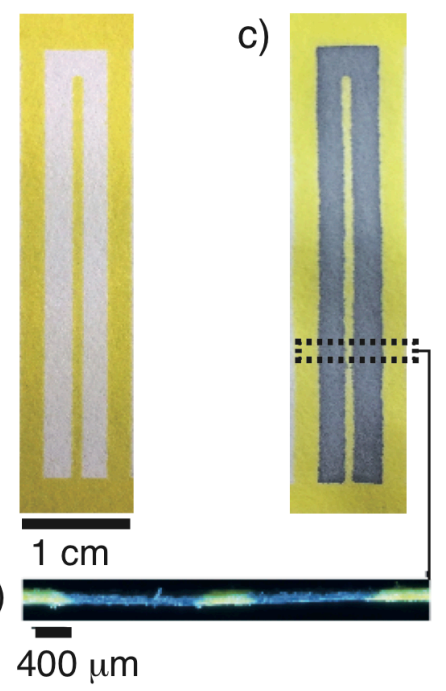

e) HEPAs

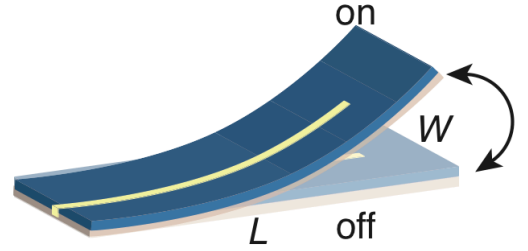

Straight

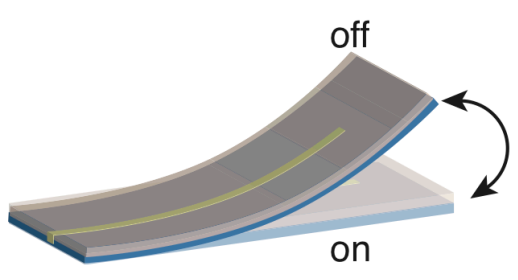

Pre-curved

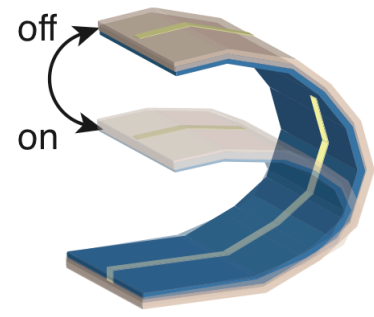

Creased-curved
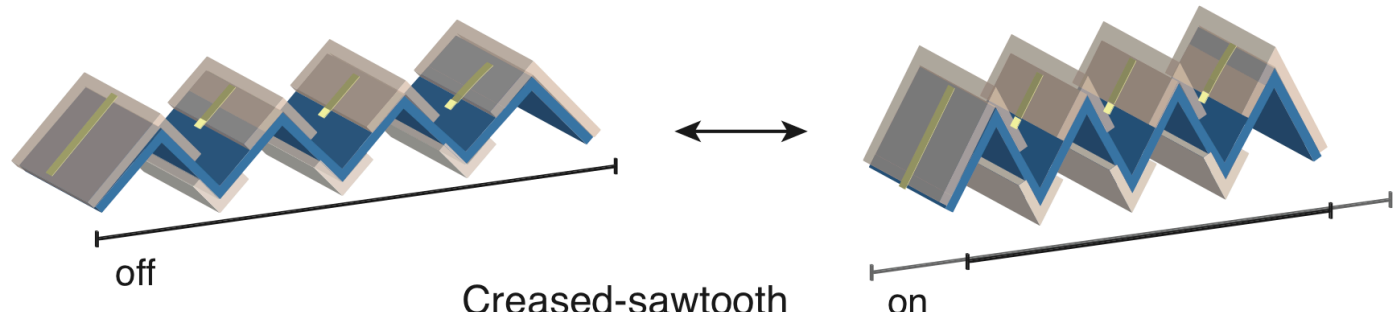

Figure 1. a) Schematic representation of the fabrication of the HEPAs: i) wax is printed and melted into the paper to form the fluidic channels; ii) a suspension of PEDOT:PSS is added to the channels; iii) the water evaporates, and deposits the conducting film of PEDOT:PSS in the channel; iv) a piece of tape is attached onto the paper/PEDOT:PSS composite to act as a strain-limiting layer. b) Photograph of the wax patterned channel. c) Photograph of the paper/PEDOT:PSS composite. d) Photograph of the cross section showing that the PEDOT:PSS is embedded in the paper channel. e) Schematic representation of the four HEPAs (straight, pre-curved, creased-curved, and creased-sawtooth), and of their motion of actuation; $L=$ length, and $W=$ width. 
a)

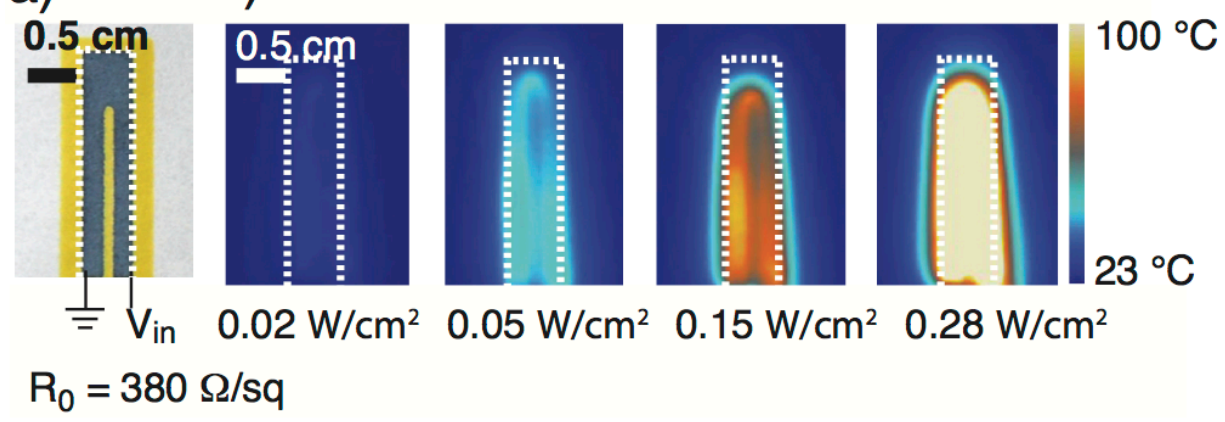

c)

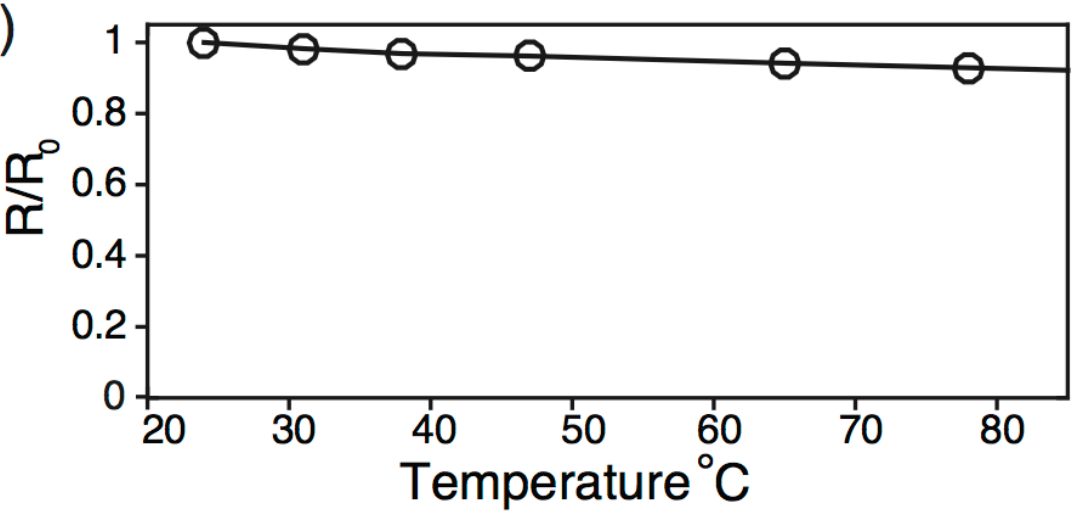

Figure 2. a) Photograph of the paper/PEDOT:PSS composite (the conducting path) embedded in a sheet of paper. The dashed lines indicate the borders of the resistive element. b) IR images of this conducting path at different consumed powers. c) Normalized resistance $\left(R / R_{0}\right)$ of the conducting path as a function of temperature, measured from the IR images. 


\section{WILEY-VCH}
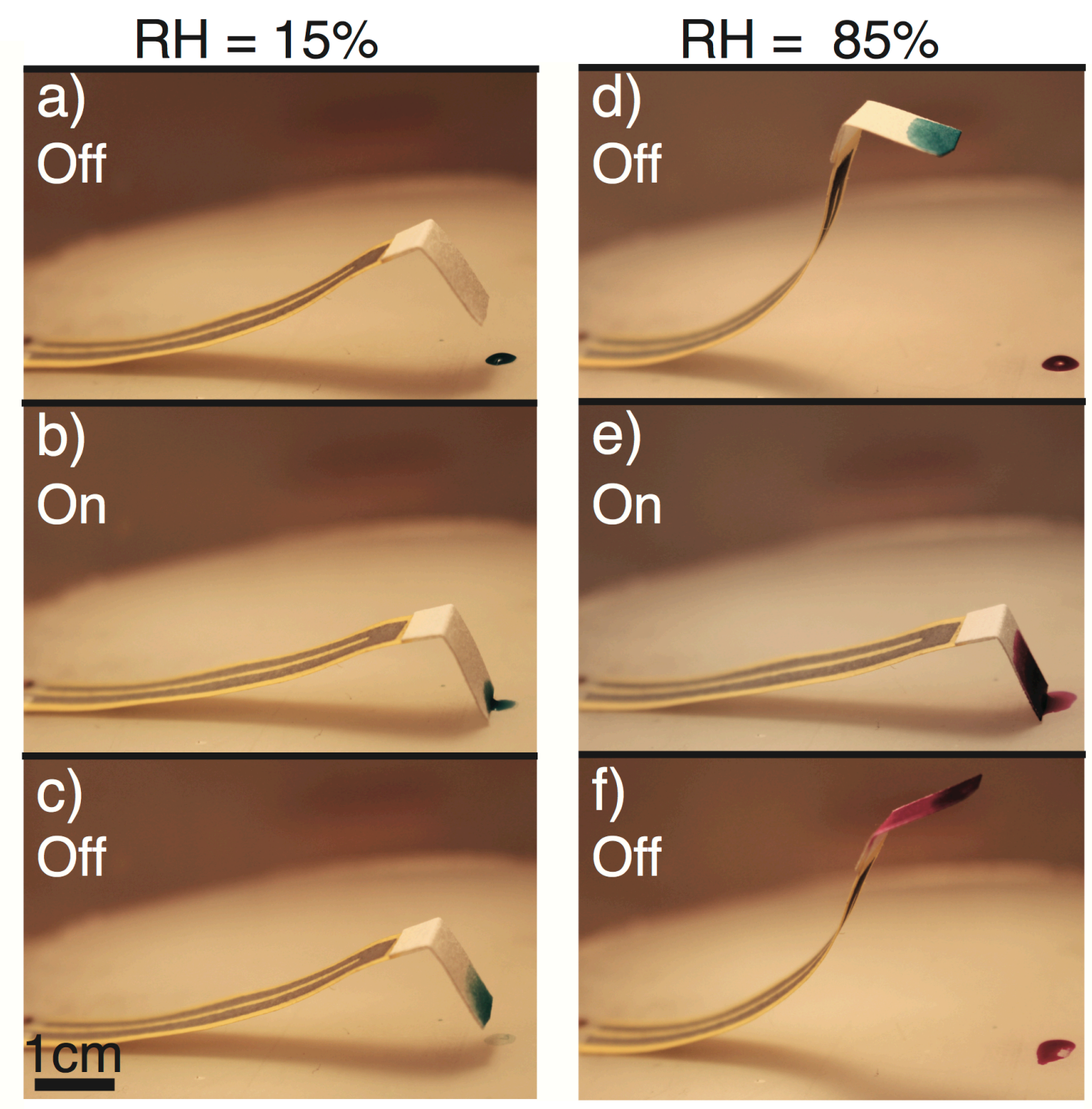

Figure 3. Time-lapse photographs of the same pre-curved HEPA (L:W=5:1 cm) operated at room temperature (at $\mathrm{P}=1 \mathrm{~W}$ and $\mathrm{I}=1.5 \mathrm{~mA}$ ), a) at $\mathrm{RH}=15 \%$, and $\mathrm{b}$ ) at $\mathrm{RH}=85 \%$. The volume of the solutions of the red and blue dye are $50 \mu \mathrm{L}$ each. 
WILEY-VCH

a)

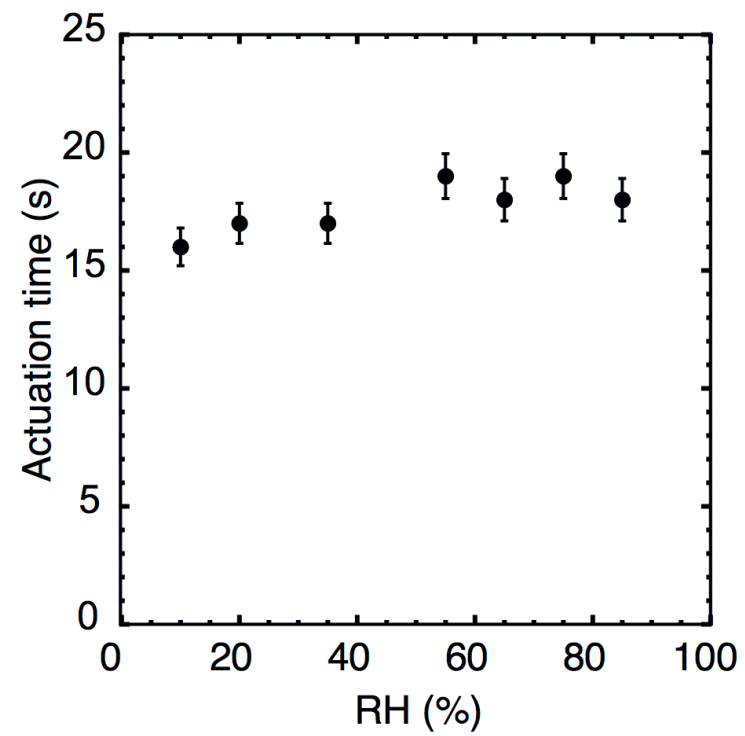

b)

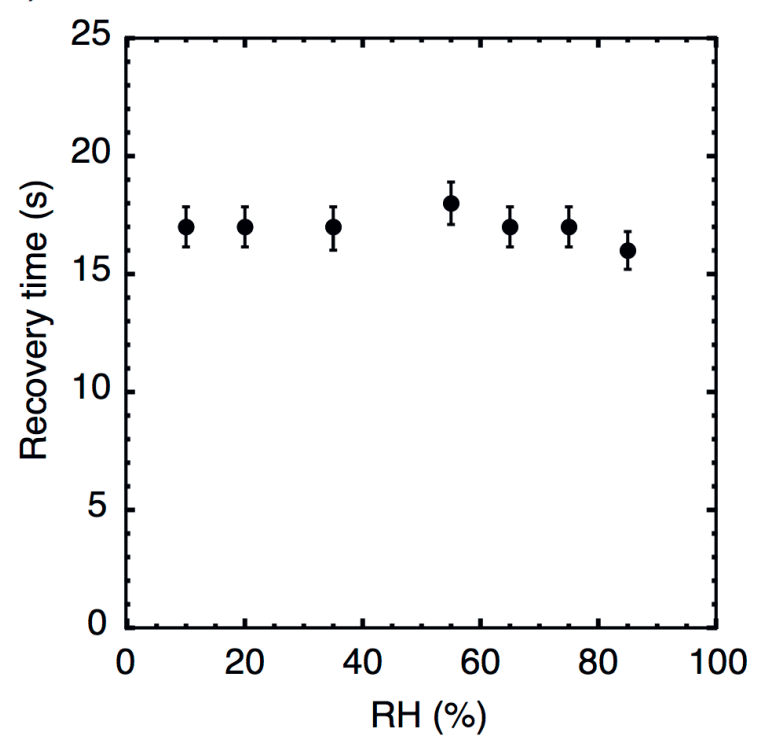

Figure 4. Actuation (a) and recover (b) times at different $\mathrm{RH}(\mathrm{P}=1 \mathrm{~W})$; in each case the time is constant within $\pm 10 \%$. 


\section{WILEY-VCH}

\section{a) Creased-curved}
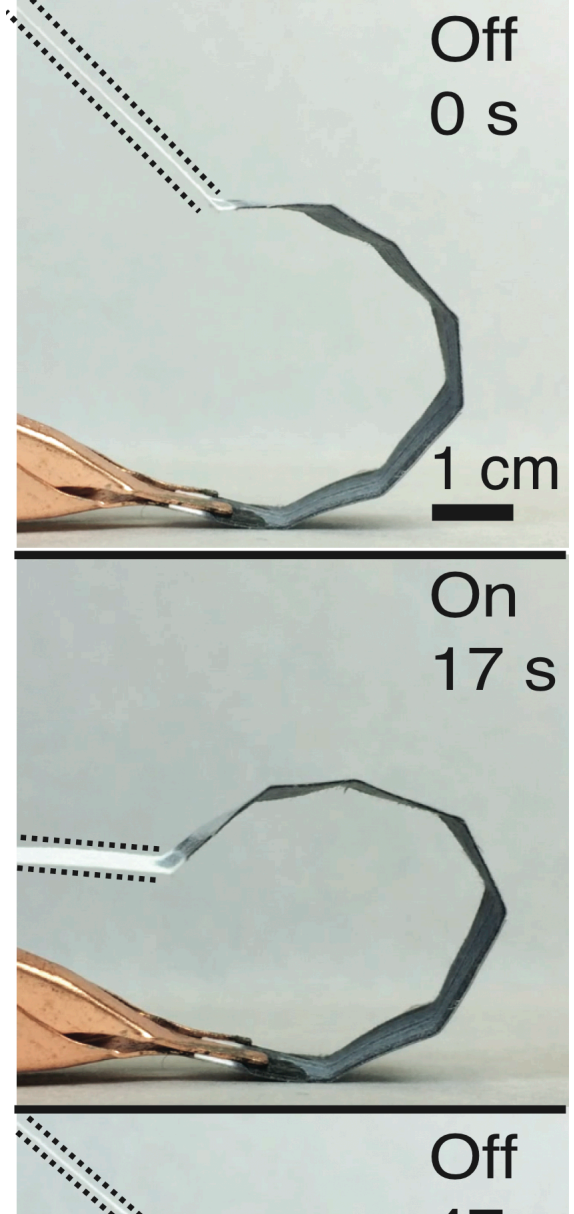

$47 \mathrm{~s}$ b) Creased-sawtooth

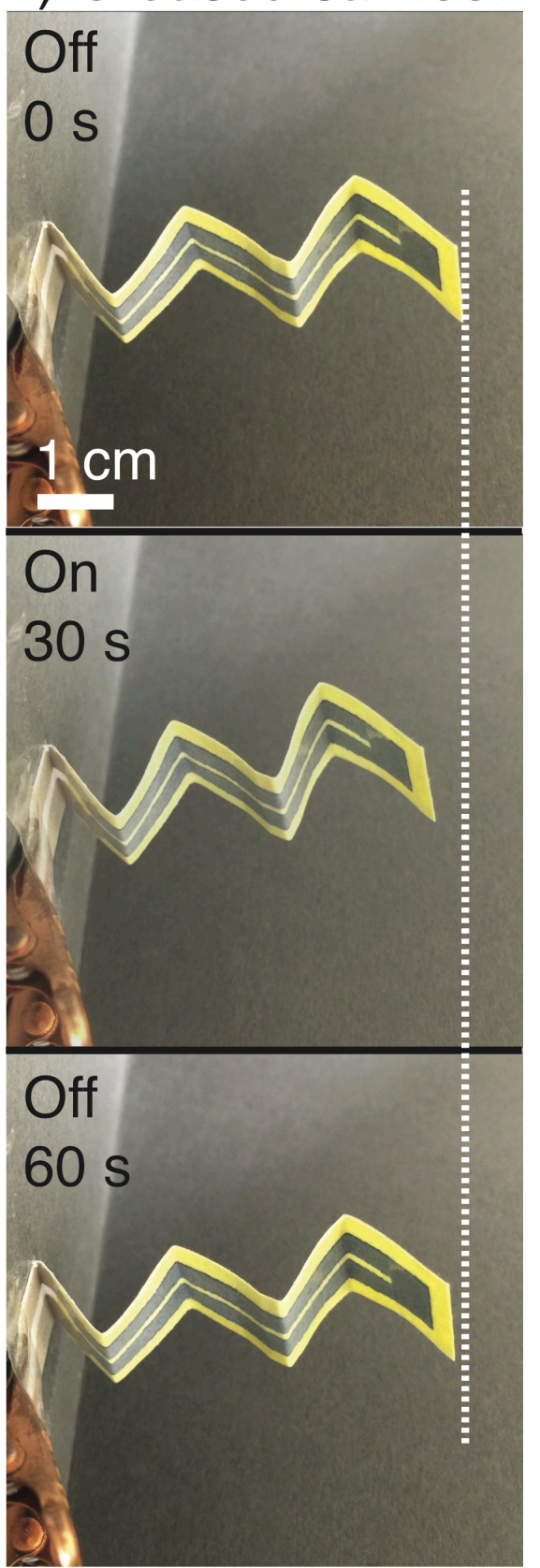

Figure 5. Time-lapse photographs of: a) creased-curved HEPA (L:W=7:0.8 cm) Dashed lines highlight the attached passive paper; b) creased-sawtooth actuator fabricated with the tape positioned on alternating side of a HEPA $(\mathrm{L}: \mathrm{W}=5: 1 \mathrm{~cm} ; \mathrm{P}=1 \mathrm{~W} ; \mathrm{I}=1.5 \mathrm{~mA} ; \mathrm{RH}=$ $40 \%)$. 


\section{WILEY-VCH}

a)

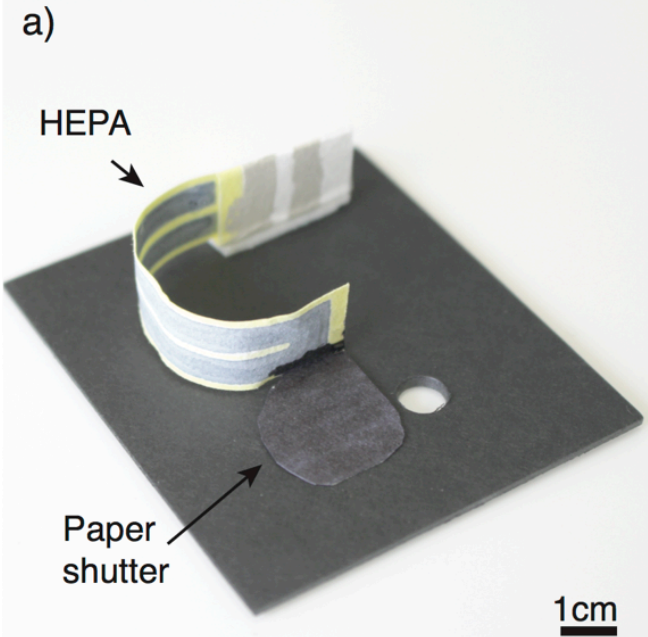

c)

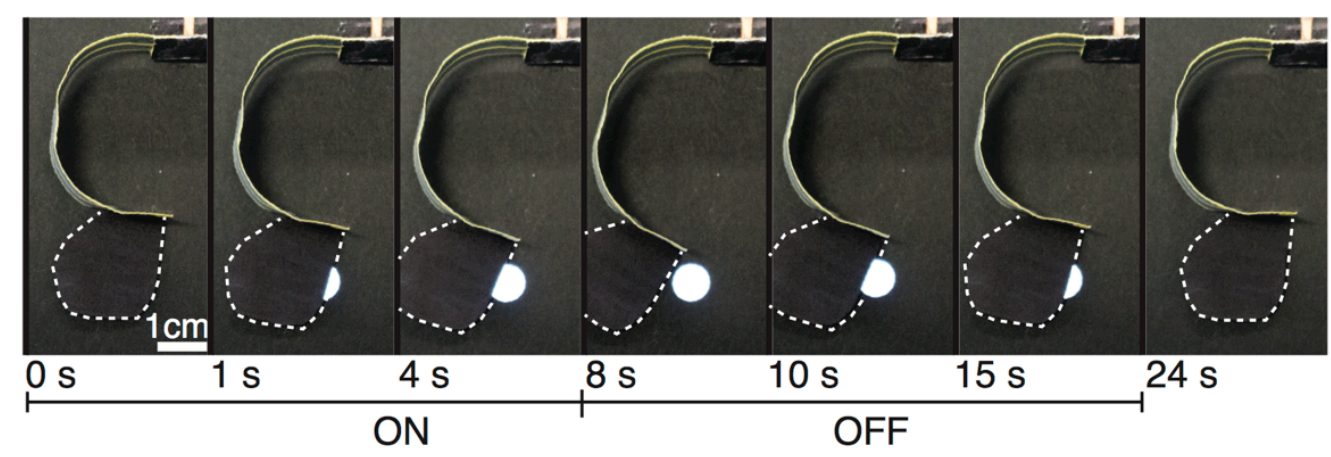

Figure 6 a) Photograph of a HEPA (L:W = 5:1 cm) optical shutter $(\mathrm{P}=1 \mathrm{~W} ; \mathrm{I}=1.5 \mathrm{~mA}$; RH $=40 \%$ ). b) Number of on / off cycles $v s$. normalized light intensity calculated from the videos of actuation. c) Time lapse photographs of the HEPA optical shutter. The device is placed on a backlit table, and the light is seen only when the shutter opens. The dashed-lines highlight the shutter area. 


\section{WILEY-VCH}

Table 1. The maximum static force measured for actuators with different L:W ratios.

\begin{tabular}{llll}
\hline $\begin{array}{l}\text { Length / width } \\
(\mathrm{cm})\end{array}$ & $\begin{array}{l}\text { Weight of the paper } \\
\text { in the actuator }(\mathrm{g})\end{array}$ & $\begin{array}{l}\text { Maximum } \\
\text { Static force / } \\
\text { weight }\left(\mathrm{Ng}^{-1} / \mathrm{g}\right)\end{array}$ & $\begin{array}{l}\text { Maximum } \\
\text { Specific force }\left(\mathrm{Ng}^{-1}\right)\end{array}$ \\
\hline $6.5 / 0.85=7.4$ & 0.050 & $1.86 / 0.19$ & 0.013 \\
$5.5 / 0.85=6.5$ & 0.043 & $3.53 / 0.36$ & 0.027 \\
$3.5 / 0.85=4.0$ & 0.027 & $5.58 /(0.57$ & 0.068 \\
\hline
\end{tabular}

